\title{
Morphologies of nanostructured bismuth sulphide and Mn (II) doped bismuth sulphide nanoparticles: characterization and application
}

\author{
Nishant AnAs Ane, Rakshit Ameta* \\ Department of Chemistry, PAHER University, Udaipur 313003 (Raj.), India
}

\begin{abstract}
Different morphologies of bismuth sulphide $\left(\mathrm{Bi}_{2} \mathrm{~S}_{3}\right)$ nanoparticles (NPs) were synthesized at room temperature using wet chemical method. The properties of bismuth sulphide $\left(\mathrm{Bi}_{2} \mathrm{~S}_{3}\right)$ nanoparticles can be controlled by different amounts of $\mathrm{Mn}^{2+}$ dopant. The synthesized nanoparticles were characterized by several techniques, such as high resolution scanning electron microscopy (HR-SEM), X-ray diffraction (XRD), transmission electron microscopy (TEM), electron diffraction (ED), and energy dispersive X-ray spectroscopy (EDS). The nanoparticles $\left(\mathrm{Bi}_{2} \mathrm{~S}_{3}\right)$ were found to have excellent activity for the UV light assisted decolorization of methyl violet dye and also helped to speed up the redox reaction of $\mathrm{Fe}(\mathrm{CN})_{6}^{3-}$ and $\mathrm{S}_{2} \mathrm{O}_{3}^{2-}$. The reactions were monitored through UV-Vis spectroscopy.
\end{abstract}

Keywords: nanostructures; dopant; metals; semiconductors; catalytic properties; surface properties

(C) Wroclaw University of Science and Technology.

\section{Introduction}

Over the last few years, semiconductor nanoparticles (NPs) have received considerable attention due to their wide applications in optical and electronic devices [1-3]. Different shapes of semiconductor nanoparticles have attracted attention in last decades, due to their effect on their magnetic and catalytic properties [4, 5]. Bismuth sulfide $\left(\mathrm{Bi}_{2} \mathrm{~S}_{3}\right)$ is a semiconductor having a direct band gap $\left(\mathrm{E}_{\mathrm{g}}\right)$ of $1.3 \mathrm{eV}[6,7]$. Doping of semiconductor nanomaterials with transition metal is important because it influences the electrical, optical, catalytic, and magnetic properties of the host semiconductor [8]. It is believed that doping a suitable metal ion, such as $\mathrm{Mn}^{2+}$, into a semiconductor host material reduces the band gap of the semiconductor, resulting in faster transition of electrons between the conduction and valence band, and due to this property, it has found many applications in nanoelectronic devices [9].

Size and morphology of nanoparticles can be changed by doping a suitable metal ion into semiconductor nanoparticles [10]. Morphology

*E-mail: rakshit_ameta@yahoo.in of nanoparticles also depends upon the temperature at which the reaction was carried out, solvents used in the synthesis and the time required to complete the reaction, but these methods are especially dependent on high temperature and pressure [11]. Different methods have been reported for preparing bismuth sulphide nanoparticles, such as sonochemical method [12], microwave irradiation [13, 14] and thermal evaporation [15]. However, these methods require very high temperature and long time. Being less toxic and harmless, bismuth and its compounds can be used in various fields of biological, cosmetic and medical industries [16].

In the present study, we report the synthesis of bismuth sulphide nanoparticles by simple wet chemical method and change in the morphology of $\mathrm{Bi}_{2} \mathrm{~S}_{3} \mathrm{NPs}$ with the doping of $\mathrm{Mn}^{2+}$ metal ions. The change in morphology of $\mathrm{Bi}_{2} \mathrm{~S}_{3} \mathrm{NPs}$ with $\mathrm{Mn}^{2+}$ dopant, caused by using polyoxyethylene 100 stearate (Myrj59) as a capping agent, has been observed. The catalytic properties of assynthesized materials were evaluated by decolorization of methyl violet dye and from the electron transfer reaction between potassium ferricyanide (PFC) and sodium thiosulphate (STS). 


\section{Experimental}

\subsection{Materials}

Bismuth nitrate, manganese acetate, polyoxyethylene 100 stearate (Myrj59), $\mathrm{Na}_{2} \mathrm{~S}$ (sodium sulphide), nitric acid, potassium ferricyanide (PFC), sodium thiosulfate (STS) and methyl violet were purchased from Sigma Aldrich. All the solutions were prepared using doubly distilled and demineralized water.

\subsection{Methods}

\subsubsection{Synthesis of $\mathrm{Mn}^{2+}$ doped bismuth sul- phide nanoparticles}

$\mathrm{Mn}^{2+}$ doped $\mathrm{Bi}_{2} \mathrm{~S}_{3}$ nanoparticles were synthesized through wet chemical method using bismuth nitrate as a source of bismuth metal, manganese acetate and sodium sulphide as sources of manganese ion and sulphur. Polyoxyethylene 100 stearate (Myrj59) acted as a stabilizing agent. Mn (10\%) doped $\mathrm{Bi}_{2} \mathrm{~S}_{3} \mathrm{NPs}$ were synthesized by using bismuth nitrate $(1.25 \mathrm{~g})$ and manganese acetate $(0.26 \mathrm{~g})$ solution in nitric acid $(20 \mathrm{~mL}) .2 \mathrm{~g}$ of polyoxyethylene 100 stearate (Myrj59) were dissolved in $30 \mathrm{~mL}$ of deionized water and stirred for half an hour to form a homogeneous solution. $1.3 \mathrm{~g}$ of $\mathrm{Na}_{2} \mathrm{~S}$ was dissolved in $10 \mathrm{~mL}$ of deionized water. Thereafter, $\mathrm{Na}_{2} \mathrm{~S}$ solution was added to the Myrj59 solution under stirring. To this mixture, bismuth nitrate and manganese acetate solution were added dropwise. The reaction mixture was stirred for $5 \mathrm{~h}$. The resulting precipitate was separated by centrifugation at $10000 \mathrm{rpm}$ for $10 \mathrm{~min}$, washed with sodium hydroxide, ethanol, water and acetone, and dried at $60{ }^{\circ} \mathrm{C}$ to $70{ }^{\circ} \mathrm{C}$ to obtain $\mathrm{Mn}^{2+}$ doped $\mathrm{Bi}_{2} \mathrm{~S}_{3}$ black powder. Similarly, for comparison $\mathrm{Mn}$ doped (5\%) and undoped $\mathrm{Bi}_{2} \mathrm{~S}_{3}$ nanoparticles were synthesized.

\subsubsection{Characterization of $\mathrm{Mn}^{2+}$ doped $\mathrm{Bi}_{2} \mathrm{~S}_{3}$ nanoparticles}

X-ray powder diffraction (XRD) investigation was carried out on Shimadzu XRD-6000. The samples were prepared by pressing the dried powder and the patterns were collected with a scanning rate of $2 \% \mathrm{~min}$ at $2 \theta$ ranging from $0^{\circ}$ to $80^{\circ}$. The morphology of nanoparticles was examined by transmission electron microscopy (TEM). TEM images were recorded on Philips CM200 using an operating voltage of $200 \mathrm{kV}$. High resolution scanning electron microscopy investigation was done on FEI Quanta-FEG 200 (HR-SEM). Elemental composition was determined by energy dispersive X-ray (EDX) analysis of the vacuum dried doped and undoped $\mathrm{Bi}_{2} \mathrm{~S}_{3}$ nanoparticles using a model JSM-5610 LV attached to scanning electron microscope (SEM). PerkinElmer Optima 4300 DV ICPOES was used to analyze the constituents present in traces. FT-IR spectra were recorded for $\mathrm{KBr}$ pellet on the PerkinElmer Spectrum RX1 model in the range of $4000 \mathrm{~cm}^{-1}$ to $400 \mathrm{~cm}^{-1}$. Doped and undoped $\mathrm{Bi}_{2} \mathrm{~S}_{3}$ nanoparticles catalyzed decolorization of methyl violet dye and the redox reaction of $\mathrm{Fe}(\mathrm{CN})_{6}^{3-}$ and $\mathrm{S}_{2} \mathrm{O}_{3}^{2-}$ were monitored by PerkinElmer LAMBDA 35 UV-Vis Spectrophotometer at corresponding $\lambda_{\max }$. High pressure mercury vapor $125 \mathrm{~W}$ lamp (HPMV) was used as a source of UV light for dye reduction.

\subsection{Decolorization of dye}

The experiments were carried out using ethyl violet dye as a model system. Each UV light assisted reduction experiment was carried out by taking $25 \mathrm{mg} \mathrm{Bi}_{2} \mathrm{~S}_{3}$ nanoparticles into a $250 \mathrm{~mL}$ glass UV chamber containing water jacket with $32.5 \times 10^{-4} \mathrm{~mol} \cdot \mathrm{L}^{-1}$ of dye. Analogous experiments were performed with and without undoped $\mathrm{Bi}_{2} \mathrm{~S}_{3}$ nanoparticles. The decolorization of the dye was measured by changes in its absorbance at $\lambda_{\max }$ using UV-Vis spectrophotometer.

\subsection{Redox reaction}

The reaction mixture containing as-synthesized $\mathrm{Bi}_{2} \mathrm{~S}_{3}$ nanoparticles $(7 \mathrm{mg}), 1 \mathrm{~mL}$ of $0.001 \mathrm{~mol}$ potassium ferricyanide (PFC) and $1 \mathrm{~mL}$ of $0.1 \mathrm{~mol}$ sodium thiosulfate (STS) were placed in a quartz cell with $1 \mathrm{~cm}^{3}$ path length. The reaction was monitored by UV-Vis spectrophotometer in the presence and absence of $\mathrm{Bi}_{2} \mathrm{~S}_{3}$ NPs at $25 \pm 2{ }^{\circ} \mathrm{C}$.

All experiments were repeated three times and the reproducibility was confirmed. The recyclability of the NPs was also studied. The NPs were recovered by centrifugation, washed with acetone, 


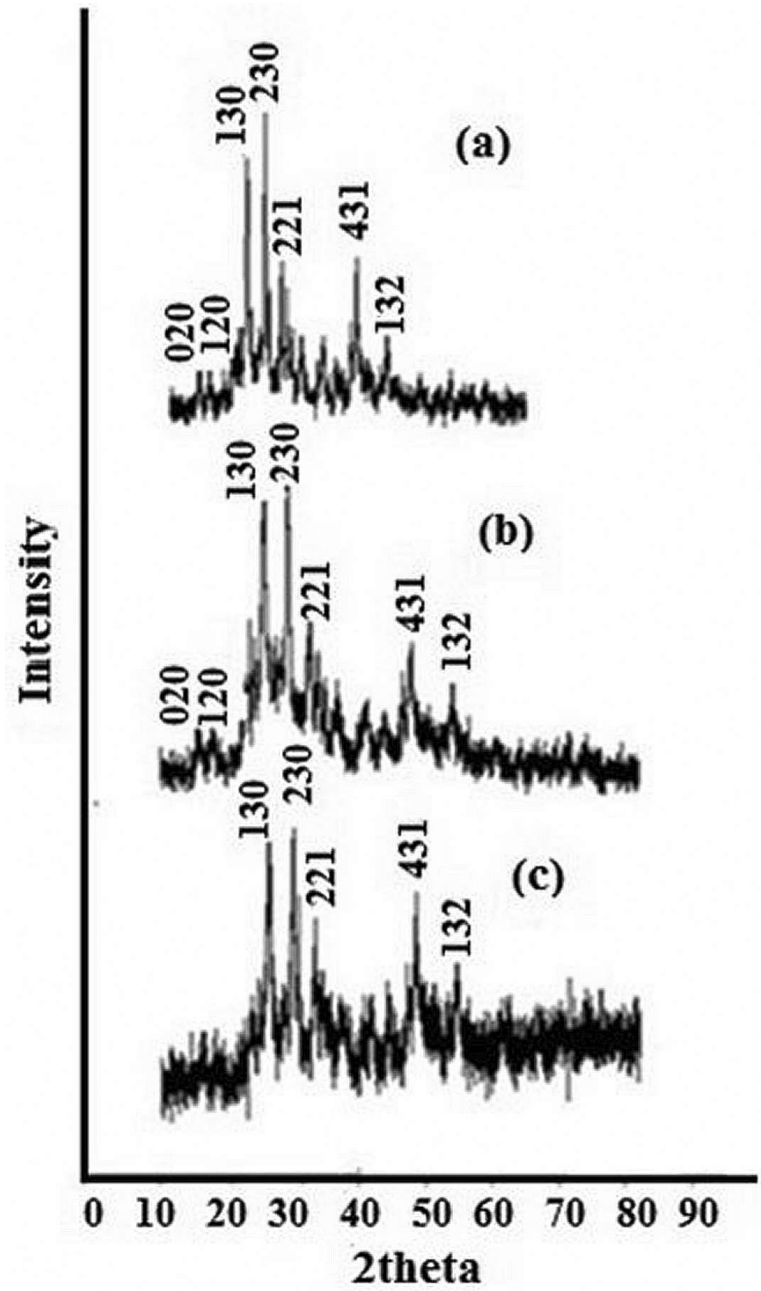

Fig. 1. XRD patterns of $\mathrm{Bi}_{2} \mathrm{~S}_{3}$ NPS (a)undoped, (b) doped with $5 \%$ Mn ions and (c) doped with $10 \% \mathrm{Mn}$ ions.

dried at $60{ }^{\circ} \mathrm{C}$ under vacuum and used for the next reaction.

\section{Results and discussion}

\subsection{XRD studies}

Fig. 1 shows the XRD patterns of assynthesized NPs. Fig. 1a is the XRD pattern of undoped $\mathrm{Bi}_{2} \mathrm{~S}_{3} \mathrm{NPs}$, whereas Fig. $1 \mathrm{~b}$ and Fig. 1c show the spectra of $5 \%$ and $10 \% \mathrm{Mn}$ ion doped $\mathrm{Bi}_{2} \mathrm{~S}_{3}$ NPs. Almost all peaks in the patterns could be indexed to a pure orthorhombic phase bismuth sulphide with the lattice parameters: $\mathrm{a}=11.132 \AA$, $\mathrm{b}=11.256 \AA$, and $\mathrm{c}=3.976 \AA$, which is in a good agreement with the literature (JCPDS Card No. 17-320). The signals of $\mathrm{Mn}^{+2}$ were not detected in the XRD spectrum of bismuth sulphide. There were no other diffraction peaks which indicates high purity and crystalline nature of the nanoparticles.

The peak due to Bragg's reflection is observed at $2 \theta$ value corresponding to $25.3^{\circ}$ and $28.9^{\circ}$. The particle size of undoped and $\mathrm{Mn}^{+2}$ doped $\mathrm{Bi}_{2} \mathrm{~S}_{3}$ nanoparticles calculated from the Debye-Scherrer equation was $20 \pm 2 \mathrm{~nm}$ :

$$
D=K \lambda /(\beta \cos \theta)
$$

where $\mathrm{K}$ is the Scherrer constant, $\lambda$ is the wavelength of the $X$-ray, $\beta$ and $\theta$ are the half width of the peak at half of the Bragg angle, respectively.

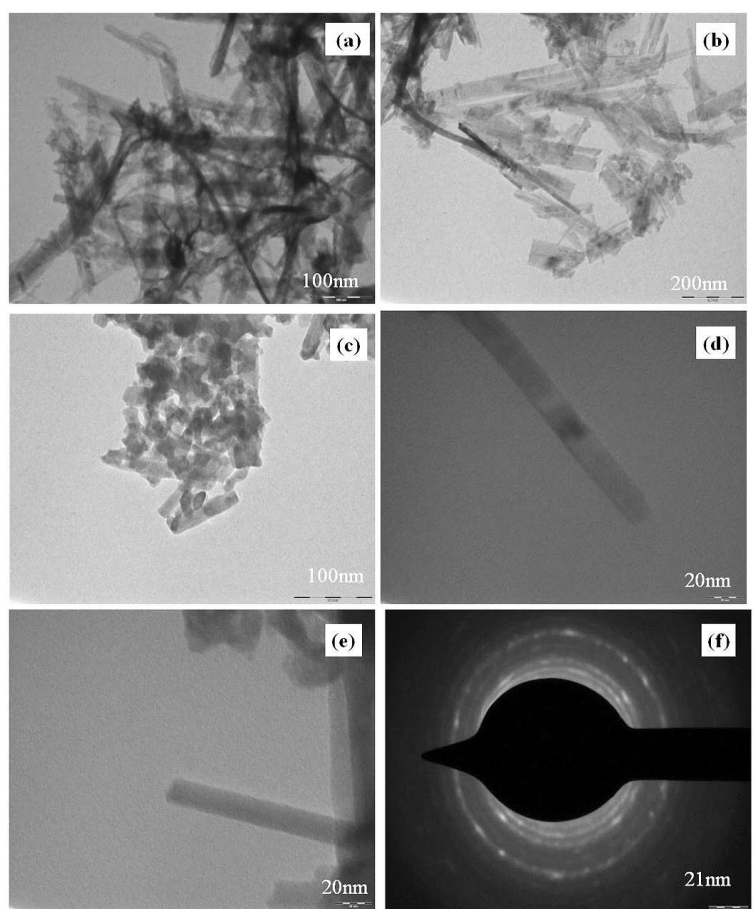

Fig. 2. TEM images of $\mathrm{Bi}_{2} \mathrm{~S}_{3} \mathrm{NPs}$ (a) undoped, (b) doped with $5 \% \mathrm{Mn}$ ions and (c) doped with $10 \% \mathrm{Mn}$ ions, (d) and (e) TEM images at higher magnification, (f) ED pattern of $\mathrm{Bi}_{2} \mathrm{~S}_{3} \mathrm{NPs}$.

\subsection{TEM analysis}

The size and morphology of the $\mathrm{Bi}_{2} \mathrm{~S}_{3}$ nanoparticles were analyzed by TEM. The TEM images 
(Fig. 2) reveal that the undoped (Fig. 2a) and $\mathrm{Mn}^{+2}$ doped $\mathrm{Bi}_{2} \mathrm{~S}_{3}$ nanoparticles consist of nanorods-like structures. When doping increased, the thickness of the rods also increased, as shown in Fig. $2 b$ and Fig. 2c. Fig. 2d and Fig. 2e are TEM images of typical $\mathrm{Bi}_{2} \mathrm{~S}_{3} \mathrm{NPs}$ at higher magnification. The diameter of the nanorods is in the range of $20 \mathrm{~nm}$ to $30 \mathrm{~nm}$, and the length is about $200 \mathrm{~nm}$ to $250 \mathrm{~nm}$. The observed rod type morphology of the product is probably due to chain type structure of bismuth sulphide. It is known that $\mathrm{Bi}_{2} \mathrm{~S}_{3}$ molecules form band-like structures as $\mathrm{Bi}$ units are connected via weaker van der Waals forces [11]. It seems that the formation of $\mathrm{Bi}_{2} \mathrm{~S}_{3} \mathrm{NPs}$ may have originated from the preferential directional growth of $\mathrm{Bi}_{2} \mathrm{~S}_{3}$ crystallites. The crystallinity of the product was also proven by SAED (Fig. 2f).

\subsection{HR-SEM analysis}

Morphology of the product was also analyzed by HR-SEM. The HR-SEM images (Fig. 3) show the formation of bar-shaped nanorods of $\mathrm{Bi}_{2} \mathrm{~S}_{3}$. Fig. 3a shows HR-SEM image of pure bismuth sulphide nanoparticles which look like bundles of thin nanorods. Fig. 3b shows HR-SEM image of $\mathrm{Mn}$ doped $\mathrm{Bi}_{2} \mathrm{~S}_{3} \mathrm{NPs}(5 \%)$ with thick nanorods. Fig. $3 \mathrm{c}$ shows cubic shaped $\mathrm{Mn}$ doped $\mathrm{Bi}_{2} \mathrm{~S}_{3} \mathrm{NPs}$ (10\%). When $\mathrm{Bi}_{2} \mathrm{~S}_{3}$ was doped with $\mathrm{Mn}^{2+}$ metal ions, the shape of $\mathrm{Bi}_{2} \mathrm{~S}_{3} \mathrm{NPs}$ has also changed. Rod type morphology of bismuth sulphide may be due to the inherent chain type structure.

\subsection{EDX analysis}

The weight percentage of $\mathrm{Mn}^{2+}$ was determined by energy dispersive X-ray analysis (EDX) (Table 1, Fig. 4). EDX analysis indicates that the well-cleaned final product is mostly composed of $\mathrm{Bi}$ and S, with no other elements (Fig. 4a). Fig. 4b and Fig. 4c are EDX images of $\mathrm{Mn}^{2+}$ doped $\mathrm{Bi}_{2} \mathrm{~S}_{3} \mathrm{NPs}$ with $5 \%$ and $10 \%$ doping of $\mathrm{Mn}$ ion, respectively.

\subsection{FT-IR spectroscopy}

The FT-IR spectra of $\mathrm{Bi}_{2} \mathrm{~S}_{3}$ NPs and pure polyoxyethylene 100 sterate (Myrj59) are given in Fig. 5. Both display the typical profile of $\mathrm{C}=\mathrm{O}$

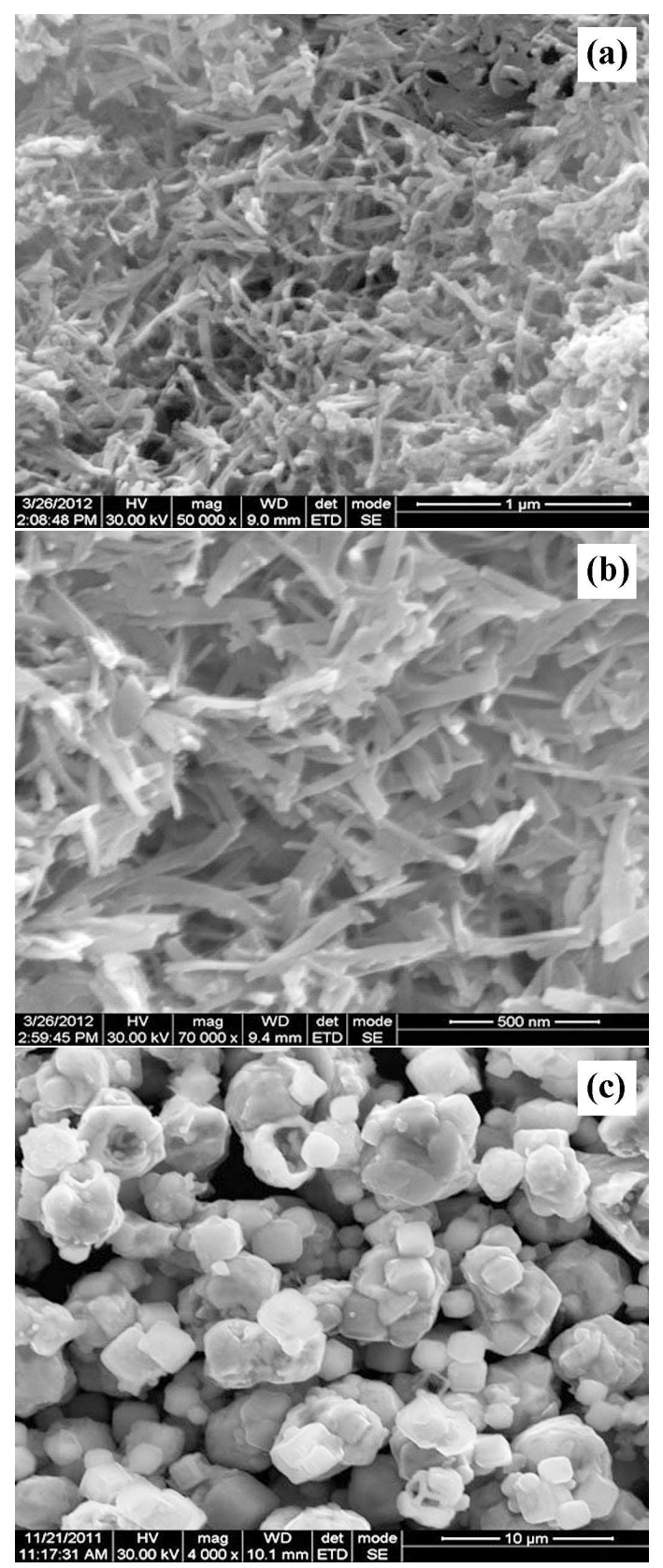

Fig. 3. HR-SEM images of (a) undoped $\mathrm{Bi}_{2} \mathrm{~S}_{3} \mathrm{NPs}$, doped with (b) $5 \% \mathrm{Mn}$ ions and (c) $10 \% \mathrm{Mn}$ ions.

group of ester in the range of $1726 \mathrm{~cm}^{-1}$. The peaks in the range of $1416 \mathrm{~cm}^{-1}$ to $1420 \mathrm{~cm}^{-1}$ are due to $\mathrm{C}-\mathrm{H}$ bending. It is seen that the peak at $1726 \mathrm{~cm}^{-1}$ shifts to $1731 \mathrm{~cm}^{-1}$ in the $\mathrm{Bi}_{2} \mathrm{~S}_{3}$ NPs. The shifts observed in the spectra can be attributed to the interaction of $\mathrm{Bi}_{2} \mathrm{~S}_{3} \mathrm{NPs}$ with the polyoxyethylene 
Table 1. Percentage Mn (at.\%, wt.\%) as a dopant in $\mathrm{Bi}_{2} \mathrm{~S}_{3}$ host determined by EDX, ICP.

\begin{tabular}{ccccc}
\hline $\begin{array}{c}\text { Amount of Mn } \\
\text { doped [at.\%] } \\
\text { used in synthesis }\end{array}$ & $\begin{array}{c}\text { Actual amount of Mn } \\
\text { in } \mathrm{Bi}_{2} \mathrm{~S}_{3} \text { matrix } \\
\text { (from EDX) [\%] }\end{array}$ & $\begin{array}{c}\mathrm{Mn} / \mathrm{Bi} \text { [at.\%] } \\
\text { determined by ICP }\end{array}$ & $\begin{array}{c}\text { Mn [wt.\%] } \\
\text { determined by ICP }\end{array}$ & $\begin{array}{c}\text { Bi [wt.\%] } \\
\text { determined by ICP }\end{array}$ \\
\hline \hline 0 & - & - & - & - \\
5 & 3.5 & 4.8 & 3.62 & 56.24 \\
10 & 8.2 & 9.3 & 9.47 & 50.57 \\
\hline
\end{tabular}

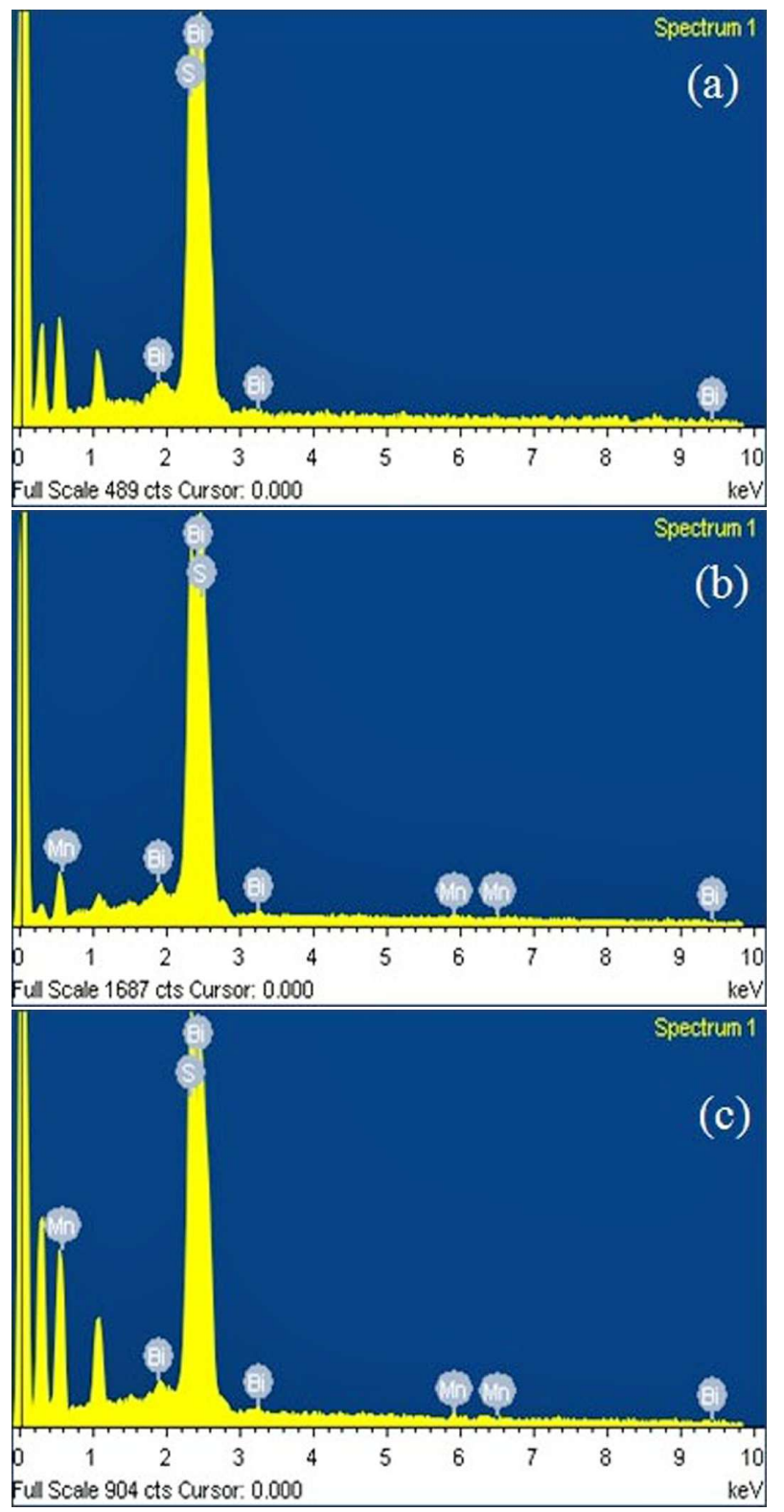

Fig. 4. EDX analysis of $\mathrm{Bi}_{2} \mathrm{~S}_{3} \mathrm{NPs}$ (a) undoped and doped with (b) $5 \% \mathrm{Mn}$ ions and (c) $10 \%$ Mn ions.

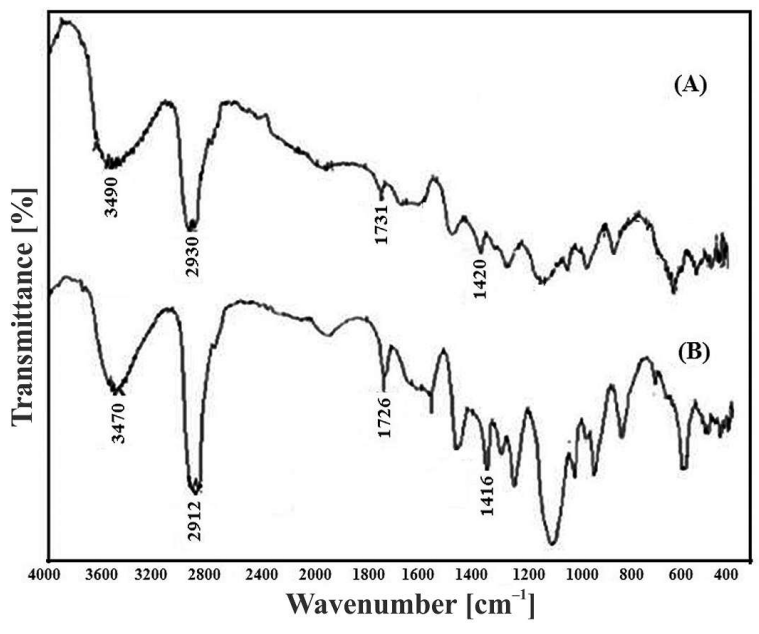

Fig. 5. FT-IR spectra of (A) $\mathrm{Bi}_{2} \mathrm{~S}_{3} \mathrm{NPs}$, (B) polyoxyethylene 100 sterate.

100 sterate. The band at $2912 \mathrm{~cm}^{-1}$ to $2930 \mathrm{~cm}^{-1}$ is characteristic of $\mathrm{C}-\mathrm{H}$ stretching. The broad band due to hydrogen bonded hydroxyl group $(\mathrm{O}-\mathrm{H})$ appears in the range of $3470 \mathrm{~cm}^{-1}$ to $3490 \mathrm{~cm}^{-1}$ and it is attributed to the complex vibrational stretching, associated with free, inter and intra molecular bound hydroxyl groups.

\subsection{Decolorization of methyl violet}

Many industries, such as textile, paint, ink, plastics, cosmetics, etc., use a variety of dyes. Dyes are lost in a waste water stream during dyeing operation. The removal of the color of waste water is a burning issue all over the world, as it creates water pollution [17].

Various chemical methods, such as oxidation, precipitation, coagulation, etc., physical processes, such as adsorption, filtration, biological techniques, such as microbial degradation, etc., are used for 


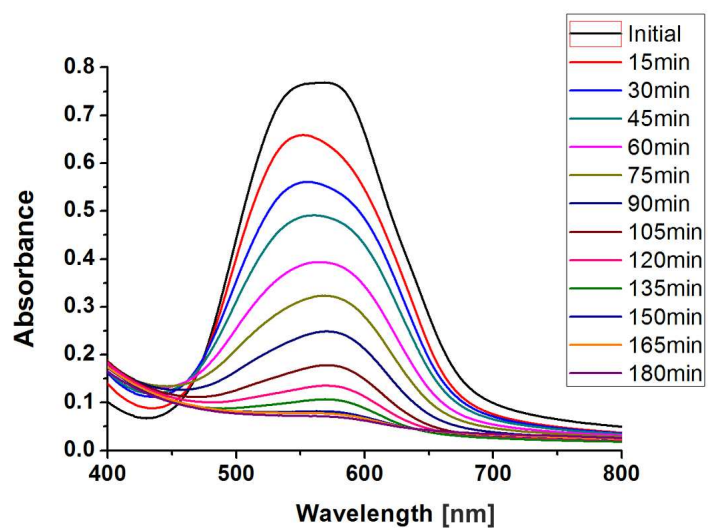

(a)

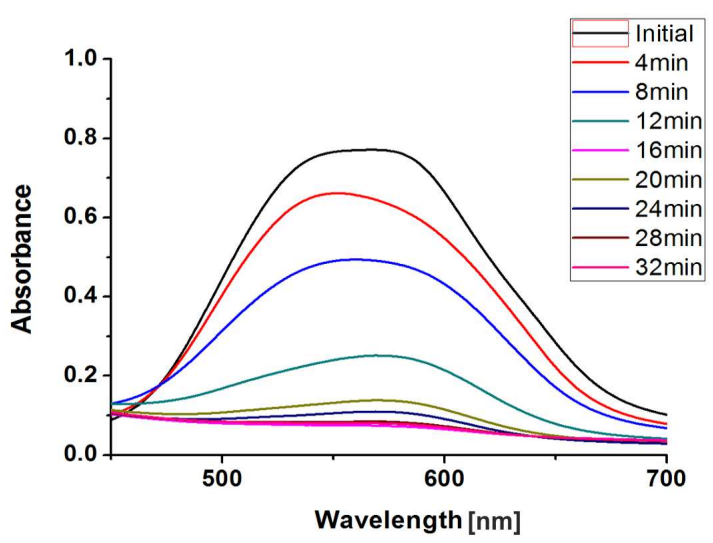

(b)

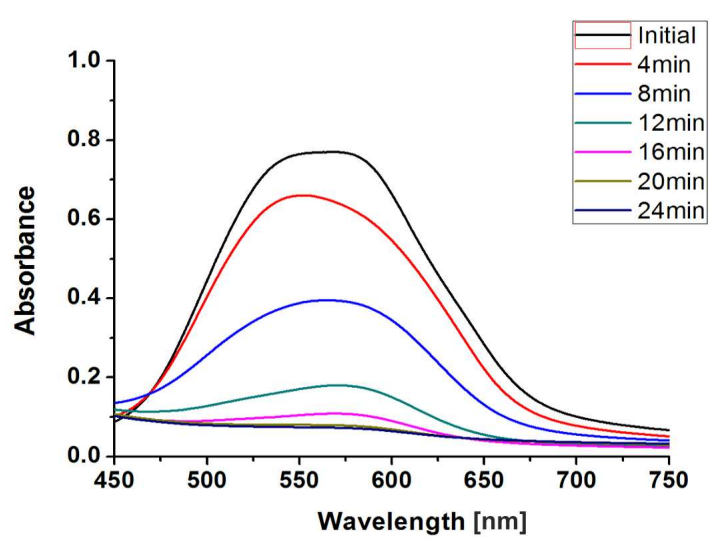

(c)

Fig. 6. UV-Vis spectra of methyl violet degradation (a) without NPs (b) with Mn doped (5\%) $\mathrm{Bi}_{2} \mathrm{~S}_{3} \mathrm{NPs}$ (c) with Mn doped (10\%) Bi ${ }_{2} \mathrm{~S}_{3} \mathrm{NPs}$.

dye removal [18, 19]. Out of these, photocatalytic degradation process has been proven to be the most efficient way to decolor the dye effluents in an ecofriendly manner [20]. Photocatalytic degradation of pollutants by semiconductors is a new and effective technique for their removal from effluents of industries [21, 22]. Photocatalysis is defined as acceleration of a photochemical reaction in the presence of a catalyst.

In the present investigation, the photocatalytic decolorization of methyl violet dye has been carried out using undoped and $\mathrm{Mn}$-doped $\mathrm{Bi}_{2} \mathrm{~S}_{3} \mathrm{NPs}$ catalyst in a photoreactor. As a representative case, the catalytic activity of $\mathrm{Bi}_{2} \mathrm{~S}_{3} \mathrm{NPs}$ was investigated in the decolorization of methyl violet dye. UVVis spectra in Fig. 6 show that before the addition of $\mathrm{Bi}_{2} \mathrm{~S}_{3} \mathrm{NPs}$, there was the maximum absorption band centered at $555 \mathrm{~nm}$. UV light alone could not induce complete decolorization of the dye. But when irradiated in presence of $\mathrm{Bi}_{2} \mathrm{~S}_{3} \mathrm{NPs}$, UV light led to complete decolorization of the dye. The absorption band at $555 \mathrm{~nm}$ decreased and disappeared. When the size of bulk metals goes to the nanoscale, electron transfer is more efficient as compared to the bulk material $[23,24]$.

As shown in the UV-Vis spectra (Fig. 6) of methyl violet, without NPs photocatalytic decolorization did not take place completely even after $7 \mathrm{~h}$. On the other hand, with NPs, the degradation was carried out in 180 min only. However, in the presence of $5 \%$ and $10 \% \mathrm{Mn}$ doped $\mathrm{Bi}_{2} \mathrm{~S}_{3} \mathrm{NPs}$ the degradation time was further reduced to $90 \mathrm{~min}$ (Fig. 6a) and 24 min (Fig. 6b), respectively.

The role of NPs in decolorization is as follows: when a photon of UV light strikes a surface of a semiconductor like $\mathrm{Bi}_{2} \mathrm{~S}_{3} \mathrm{NPs}$, a valence band electron moves to the conduction band, thus forming a positively charged hole in the valence band. The conduction band electrons and the valence band holes migrate then to the oxide surface and react with the chemisorbed $\mathrm{O}_{2}$ or $\mathrm{OH}^{-} / \mathrm{H}_{2} \mathrm{O}$ molecules to generate reactive oxygen species, such as $\mathrm{O}_{2}^{-}$, $\mathrm{HOO}^{\prime}$ and $\mathrm{OH}$ radicals which attack the dye molecules and cause their degradation [20, 24]. The mechanism for dye decolorization is similar to those discussed by Samira et al. [20] and Mohamed et al. [24].

Doping with a proper element is widely used as an effective method to tune surface states, energy 
levels, electrical, optical, structural and magnetic properties of semiconductor materials [25-27].

To control the behavior of materials, doping is used, which lies at the heart of many technologies. For this reason, researchers have begun to explore the use of dopants to influence the properties of semiconductor nanoparticles [28]. The energy from absorbed photons can be efficiently transferred to the dopants which is utilized in the excitation and increases the rate of reactions on the surface of NPs [29]. Although the role of Myrj59 is only to cap the $\mathrm{Bi}_{2} \mathrm{~S}_{3}$ NPs and to rule out the possibilities of decolorization by Myrj59, an experiment was performed with using it. No significant decrease in the absorbance was observed with using Myrj59.

\subsection{Reaction between potassium ferri- cyanide and sodium thiosulfate}

The electron transfer reaction between $\mathrm{Fe}(\mathrm{CN})_{6}^{3-}$ and $\mathrm{S}_{2} \mathrm{O}_{3}^{2-}$ was catalyzed by a metal like $\mathrm{Pt}$ [30-32], Ni [33]. This reaction was performed for the first time in the presence of $\mathrm{Bi}_{2} \mathrm{~S}_{3} \mathrm{NPs}$. The characteristic absorption of $\mathrm{Fe}(\mathrm{CN})_{6}^{3-}$ was observed at $420 \mathrm{~nm}$. When reaction took place between $\mathrm{Fe}(\mathrm{CN})_{6}^{3-}$ and $\mathrm{S}_{2} \mathrm{O}_{3}^{2-}$, the intensity of the corresponding peak $(420 \mathrm{~nm})$ decreased with time. In both the reactions, absorption was measured at time intervals of $3 \mathrm{~min}$. In presence of Mn doped $\mathrm{Bi}_{2} \mathrm{~S}_{3} \mathrm{NPs}(10 \%$ ) (Fig. 7a), there was a continuous decrease in absorbance at $420 \mathrm{~nm}$ with respect to time and after $24 \mathrm{~min}$, the peak completely disappeared. In case of $5 \% \mathrm{Mn}$ doped $\mathrm{Bi}_{2} \mathrm{~S}_{3}$ (Fig. 7b) completion of the reaction took $39 \mathrm{~min}$. However, in the absence of $\mathrm{Bi}_{2} \mathrm{~S}_{3}$ the reaction was proceeding very slowly and did not take place even after $6 \mathrm{~h}$ (Fig. 7c). On the basis of these observations it can be concluded that in presence of $\mathrm{Bi}_{2} \mathrm{~S}_{3} \mathrm{NPs}$, redox reactions proceed faster owing to efficient electron transfer due to the larger surface area of $\mathrm{Bi}_{2} \mathrm{~S}_{3} \mathrm{NPs}$.

\section{Conclusions}

Our experimental observations clearly indicate that $\mathrm{Mn}^{+2}$ doped $\mathrm{Bi}_{2} \mathrm{~S}_{3}$ nanoparticles have been successfully synthesized using a simple wet

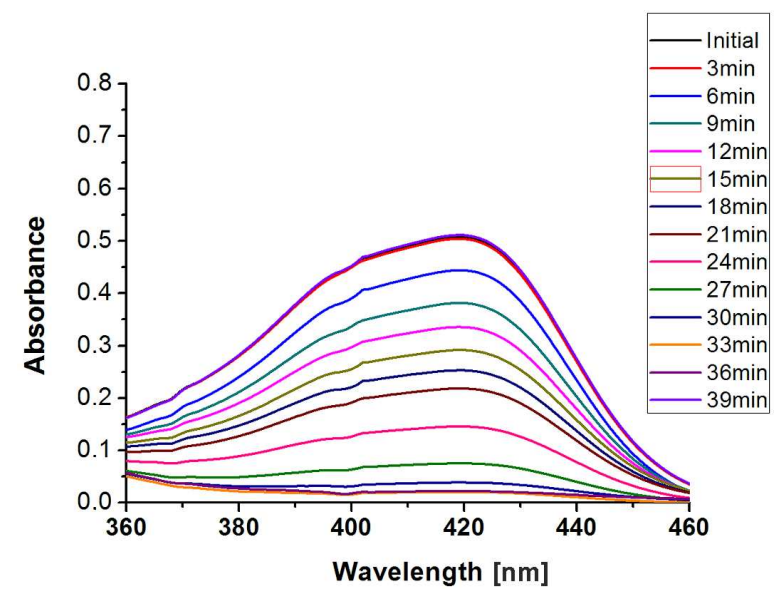

(a)

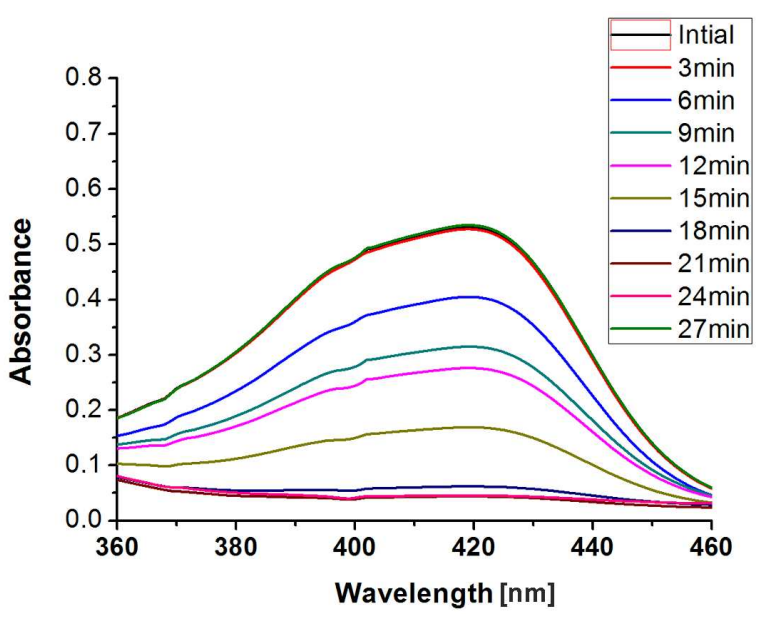

(b)

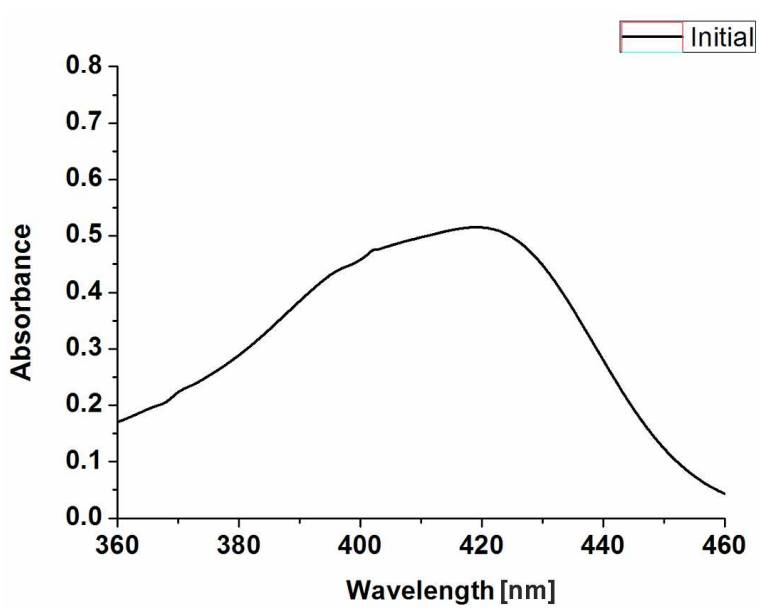

(c)

Fig. 7. UV spectra of redox reaction between $\mathrm{Fe}(\mathrm{CN})_{6}^{3-}$ and $\mathrm{S}_{2} \mathrm{O}_{3}^{2-}$ (a) with Mn doped (10\%) $\mathrm{Bi}_{2} \mathrm{~S}_{3} \mathrm{NPs}$, (b) with Mn doped (5\%) $\mathrm{Bi}_{2} \mathrm{~S}_{3} \mathrm{NPs}$, (c) without $\mathrm{Bi}_{2} \mathrm{~S}_{3} \mathrm{NPs}$. 
chemical method. The TEM study revealed that thin rod shaped NPs were obtained in cases of undoped $\mathrm{Bi}_{2} \mathrm{~S}_{3} \mathrm{NPs}$, while thick nanorods were formed in the presence of $5 \%$ and $10 \%$ Mn dopant ions. HR-SEM image also supported this observation. In HR-SEM images with $10 \%$ loading of Mn dopant, NPs showed cubic shaped morphology. The present study allows us to conclude that multiple functionalities can be induced in NPs by doping or varying the dopant ion concentration. Further, $\mathrm{Bi}_{2} \mathrm{~S}_{3} \mathrm{NPs}$ also helped in speeding up decolorization of methyl violet dye and changed the order of the redox reaction.

\section{Acknowledgements}

The Authors thank to the IIT Bombay and the IIT Madras for TEM, HR-SEM and EDX analysis.

\section{References}

[1] Colvin V.L., Schlamp M.C., Alivisatos A.P., $N a-$ ture, 370 (1994), 354.

[2] Mane R.M., Mane S.R., Kharade R.R., Bhosale P.N., J. Alloy. Compd., 491 (2010), 321.

[3] Manea R.M., Ghanwata V.B., Kondalkara V.V., Khota K.V., Manea S.R., PATILB P.S., BhosALEA P.N., ICMPC-2014, 6 (2014), 1285.

[4] Krahne R., Manna L., Morello G., Figuerola A., George C., DeKa S., Physical Properties of Nanorods, Springer-Verlag, Berlin Heidelberg, 2013.

[5] Perez-Juste J., Pastoria-Santos I., LizMarzan L.M., Mulvaney P., Coord. Chem. Rev., 249 (2005), 1870.

[6] Murray C.B., Kagan C.R., Bawendi M.G., Annu. Rev. Mater. Sci., 30 (2000), 545.

[7] Zhang J.Z., J. Phys. Chem. B, 104 (2000), 7239.

[8] Nag A., Chakraborty S., Sarma D.D., J. Am. Chem. Soc., 130 (2008), 10605.

[9] Dixita N., Anasane N., Chavda M., Bodas D., Soni H.P., Mater. Res. Bull., 48 (2013), 2259.

[10] Gao Y., Cao C., Dai L., Luo H., Kanehira M., Dingd Y., WANG Z.L., Energ. Environ. Sci., 5 (2012), 8708 .

[11] Wang H., Zhu J.J., Zhu J.M., Chen H.Y., J. Phys. Chem. B, 106 (2002), 3848.
[12] Wang S.Y., Du Y.W., J. Cryst. Growth, 236 (2002), 627.

[13] Liao X.H., Wang H., Zhu J.J., Chen H.Y., Mater. Res. Bull., 36 (2001), 2339.

[14] Liao X.H., ZhU J.J., Chen H.Y., Mater. Sci. Eng. B$A d v ., 85$ (2001), 85.

[15] Rincon M.E., SANChEZ M.P., GEORGE J., Sanchez A., NaIR P.K., J. Solid State Chem., 136 (1998), 167.

[16] Mohan R., Nat. Chem., 2 (2010), 241.

[17] Tekbas M., Bektas N., Yatmaz H.C., Desalination, 249 (2009), 205.

[18] Karthik V., Saravana K., Bharathi P., DhaRanya V., Meiaraj C., JCHPS, 7 (2014), 301.

[19] Saratale R.G., Saratale G.D., Chang J.S., GovindWAR S.P., J. Hazard. Mater., 166 (2009), 1421.

[20] Samira S., Raja A., Mohan P., Modak J.M., J. Thermodyn. Catal., 3 (2012), 2157.

[21] Mahyar A., Behnajady M.A., Modirshahla N., Photochem. Photobiol., 87 (2011), 795.

[22] Shivaraju H.P., Int. J. Environ. Sci. Te, 5 (2011), 911.

[23] Pande S., Ghosh S.K., Nath S., Praharaj S., Jana S., Panigrahi S.J., J. Colloid Interf. Sci., 299 (2006), 421.

[24] Mohamed R.M., McKinney D.L., Sigmund W.M., Mat. Sci. Eng. R, 73 (2012), 1.

[25] Chen Z., Li D., Zhang W., Shao Y., Chen T., Sun M., Fu X., J. Phys. Chem. C, 113 (2009), 4433.

[26] Wang X., Shen S., Jin S., Yang J., Li M., Wang X., Hana H., Li C., Phys. Chem. Chem. Phys., 15 (2013), 19380.

[27] Jia Y., Shen S., Wang D., Wang X., Shi J., Zhang F., HAN H., Li C., J. Mater. Chem. A, 1 (2013) 7905.

[28] Alivisatos A.P., Science, 271 (1996), 933.

[29] Pradhan N., Goorskey D., Thessing J., Peng X.G., J. Am. Chem. Soc., 127 (2005), 17586.

[30] Narayanan R., El-Sayed M.A., J. Phys. Chem. B, 107 (2003), 12416.

[31] Yang W., Ma Y., Tang J., Yang X., Colloid. Surface. A, 302 (2007), 628.

[32] Pal A., Shah S., Chakraborty D., Devi S., Aust. J. Chem., 61 (2008), 833.

[33] Rathore P.S., RAThore S., PATIDAR R., THAKORE S., Catal. Lett., 144 (2014), 439.

Received 2016-05-07 Accepted 2017-01-21 